J Neurosurg (Suppl 2) 121:102-109, 2014

(C) AANS, 2014

\title{
Gamma Knife surgery for treating brain metastases arising from hepatocellular carcinomas
}

\author{
Clinical article
}

\author{
Eun Suk Park, M.D., ${ }^{1}$ Do Hoon Kwon, M.D., ${ }^{2}$ Jun Bum Park, M.D., ${ }^{1}$ Do Hee Lee, Ph.D., 2 \\ Young Hyun Cho, M.D., ${ }^{2}$ Jeong Hoon Kim, M.D., ${ }^{2}$ and Chang Jin Kim, M.D. ${ }^{2}$ \\ ${ }^{1}$ Department of Neurosurgery, Ulsan University Hospital, University of Ulsan College of Medicine, Ulsan; \\ and ${ }^{2}$ Department of Neurological Surgery, Asan Medical Center, University of Ulsan College of Medicine, \\ Seoul, Korea
}

\begin{abstract}
Object. Brain metastases from hepatocellular carcinoma (HCC) are rare, and the evidence of the effectiveness of Gamma Knife surgery (GKS) in this disease is lacking. The authors report their institutional experience with GKS in patients with brain metastases from HCCs.

Methods. The authors retrospectively reviewed the medical records of 73 consecutive patients who had a combined total of 141 brain metastases arising from HCCs and were treated with GKS. Sixty-four (87.7\%) patients were male, and the mean age of the patients was 52.5 years (range 30-79 years). The mean tumor volume was $7.35 \mathrm{~cm}^{3}$ (range $0.19-33.7 \mathrm{~cm}^{3}$ ). The median margin dose prescribed was $23 \mathrm{~Gy}$ (range 15-32 Gy). Univariate and multivariate survival analyses were performed to identify possible prognostic factors of outcomes.

Results. The estimated rate of local tumor control was $79.6 \%$ at 3 months after GKS. The median overall survival time after GKS was 16 weeks. The actuarial survival rates were $76.7 \%, 58.9 \%$, and $26.0 \%$ at 4,12 , and 24 weeks after GKS, respectively. In the univariate analysis, an age of $\leq 65$ years, Child-Pugh Class A (pertaining to liver function), high Karnofsky Performance Scale score ( $\geq 70)$, and low Radiation Therapy Oncology Group recursive partitioning analysis class (I or II) were positively associated with the survival times of patients. No statistically significant variable was identified in the multivariate analysis.

Conclusions. Although survival was extremely poor in patients with brain metastases from HCCs, GKS showed acceptable local tumor control at 3 months after the treatment. The authors suggest that GKS represents a noninvasive approach that may provide a valuable option for treating patients with brain metastases from HCCs. (http://thejns.org/doi/abs/10.3171/2014.7.GKS141507)
\end{abstract}

\section{KeY WoRds - neoplasm metastases • radiosurgery - Gamma Knife surgery stereotactic radiosurgery $•$ hepatocellular carcinomas $•$ oncology}

$\mathrm{H}$ EPATOCELlular carcinoma (HCC) is one of the most common cancers worldwide. It is the fifth most common form of cancer globally and the third most common cause of cancer-related deaths. ${ }^{19}$ Incidence of HCC is particularly high in Asia and Africa, where hepatitis B infections are the most prevalent. Be-

\footnotetext{
Abbreviations used in this paper: $\mathrm{AFP}=$ alpha fetoprotein; GKS = Gamma Knife surgery; HCC $=$ hepatocellular carcinoma; KPS = Karnofsky Performance Scale; RPA = recursive partitioning analysis; RTOG = Radiation Therapy Oncology Group; SRS = stereotactic radiosurgery; WBRT $=$ whole-brain radiotherapy.
}

cause of hepatitis $\mathrm{C}$ infections, $\mathrm{HCC}$ rates have significantly increased in Europe, Japan, and North America. ${ }^{2}$ Despite the high prevalence of HCC, brain metastases from $\mathrm{HCC}$ are rarer than brain metastases arising from other common cancers. ${ }^{1,20}$ The reported incidence of brain metastases from $\mathrm{HCC}$ is usually less than $1 \%$ (range $0.2 \%-2.2 \%)^{4,10,12,13,17}$ because HCC tends to spread to other sites, such as the lung, abdominal lymph nodes, and bone. ${ }^{2}$ Therapeutic advances in the management of HCC have improved the survival of patients with the disease..$^{2,19}$ Therefore, the incidence of brain metastases from HCC is expected to increase. 
To manage brain metastases from HCCs, whole-brain radiotherapy (WBRT), resection, or both have been used as standard treatments. However, the management of brain metastases originating from HCCs is not well established. 2,15,22 Moreover, patients with brain metastases from HCCs can often not undergo surgery because of liver dysfunction, associated coagulopathy, and other medical problems. Recently, stereotactic radiosurgery (SRS) using the Gamma Knife has been adopted as an effective and safe treatment option for patients with brain metastases, especially those with medical comorbidities. Nevertheless, evidence of the effectiveness of Gamma Knife surgery (GKS) for the management of brain metastases from HCCs is lacking. Here, we review our institutional experience with GKS in patients with brain metastases from HCCs.

\section{Methods}

\section{Patient Population}

Between January 1993 and December 2012, 73 consecutive patients with a combined total of 141 brain metastases originating from HCCs were treated with GKS at our institute. All 73 patients fulfilled the following criteria: 1) $\mathrm{HCC}$ diagnosis with histological confirmation based on resection or biopsy specimens of the primary liver mass or clinical confirmation based on clinical and radiological data,${ }^{15}$ and 2) diagnosis of brain metastases on brain MRI and/or CT scans showing homogeneous contrast enhancement or hemorrhagic lesions suggestive of tumor bleeding and an associated contrast-enhancing solid mass portion. A retrospective review was performed of the records of these patients to assess the efficacy of GKS with approval of the institutional research ethics board.

\section{Radiosurgery Technique and Follow-Up Protocol}

A Leksell stereotactic coordinate frame (Elekta AB) was applied to the head of a patient under local anesthesia and mild oral sedation. Tumors were localized on highresolution contrast-enhanced MRI and CT scans. Multiple-dose planning was accomplished using a computer dose-planning system (Kula, GammaPlan, GammPlan PFX system; Elekta) during the study period. Gamma Knife surgery was performed using models B, C, or Perfexion (Elekta) in the order of time sequence.

The dose prescription was determined in accordance with the Radiation Therapy Oncology Group (RTOG) protocol, ${ }^{21}$ with small modifications based on factors such as volume, number, and location of lesions, prior radiation therapy, and the predicted dose-response relationship for brain parenchymal necrosis. The most important consideration in dose prescription was total tumor volume. The mean total tumor volume was $7.3 \mathrm{~cm}^{3}$ (range $0.2-33.7$ $\left.\mathrm{cm}^{3}\right)$. The mean number of lesions per patient was 1.9 (range 1-6), and the mean volume of individual lesions was $3.8 \mathrm{~cm}^{3}$ (range $0.2-33.7 \mathrm{~cm}^{3}$ ). The median tumor margin dose was 23 Gy (range 15-32 Gy), with a median isodose line of $50 \%$ (range 40\%-75\%).

All patients received methylprednisolone for up to 7 days to prevent acute brain swelling after GKS. Follow-up clinical examinations were performed every 1-3 months after GKS. Follow-up MRI was performed at the first clinical follow-up and every 3 months thereafter.

\section{Outcome Evaluation and Statistical Analysis}

Tumor control was assessed by comparison of followup MRI scans with pre-GKS scans. Response was classified as a complete response (tumor disappearance), partial response (tumor volume reduction of $\geq 30 \%$ ), stable disease (volume reduction of $<30 \%$ or enlargement by $<30 \%$ ), or disease progression (volume enlargement by $\geq 30 \%$ ). Complete response, partial response, and stable disease at the final follow-up visit were indicative of tumor control. Distant recurrences were defined as any newly developed metastatic lesions remotely located from previously treated lesions. Overall survival time was defined as the interval between the first GKS and death. When pertinent information was not available in the clinical records, a telephone interview was conducted with the patient or a family member.

Overall survival times were estimated using KaplanMeier survival plots. Differences in the overall survival between groups were assessed by the log-rank test. Multivariate predictors of survival were determined using the Cox proportional hazards model. A $p$ value $<0.05$ was considered statistically significant. Independent variables were tested categorically and included age (cutoff value of 65 years), alpha fetoprotein (AFP) levels (cutoff value of $400 \mathrm{ng} / \mathrm{ml}$ ), Child-Pugh class (B or C vs A), number of brain metastases (single vs multiple), presence of extracranial metastases, Karnofsky Performance Scale (KPS) scores (cutoff value of 70), RTOG RPA class (I or II vs III), presence of tumor bleeding, and total volume of brain metastases (cutoff value of $14 \mathrm{~cm}^{3}$ ). All statistical analyses were performed using Statistical Product and Service Solution (version 21). The R package (version 3.0.2, R Foundation for Statistical Computing) was used to plot KaplanMeier curves.

\section{Results}

\section{Patient Characteristics}

Table 1 summarizes the characteristics of the patients. They included 64 men and 9 women, with a median age of 52.5 years (range 30-79 years). Viral hepatitis infection was detected in most of the patients (91.8\%) in a serological study, and hepatitis B virus infection was highly prevalent (62 patients, $84.9 \%$ ). According to the ChildPugh classification for the severity of liver function, liver function in 50 patients $(68.5 \%)$ was classified as Class A, Class B in 19 (26.0\%), and Class C in 4 (5.5\%). Elevated AFP levels (> $400 \mathrm{ng} / \mathrm{ml}$ ) were observed in 49 patients (67.1\%). The most common presenting symptoms were new-onset neurological deficit, followed by headache and seizure, and most of the lesions (93.2\%) were symptomatic. Fifty-six patients (76.7\%) had a KPS score of 70 or more. In total, 141 brain metastases were identified in the 73 patients, 41 of whom $(56.2 \%)$ presented with a single brain lesion. Tumor bleeding was observed in 35 patients (47.9\%). At the time of diagnosis of a brain metastasis, most patients (93.2\%) had metastases in other organs. The 
TABLE 1: Summary of patient characteristics

\begin{tabular}{|c|c|}
\hline Characteristic & Study Patients* \\
\hline mean age, yrs (range) & $52.5(30-79)$ \\
\hline \multicolumn{2}{|l|}{ age (yrs) } \\
\hline$\leq 65$ & $64(87.7)$ \\
\hline$>65$ & $9(12.3)$ \\
\hline $\mathrm{M} / \mathrm{F}$ ratio & $64(87.7) / 9(12.3)$ \\
\hline \multicolumn{2}{|l|}{ etiology } \\
\hline hepatitis B & $62(84.9)$ \\
\hline hepatitis C & $5(6.9)$ \\
\hline other & $6(8.2)$ \\
\hline AFP $>400 \mathrm{ng} / \mathrm{ml}$ & $49(67.1)$ \\
\hline \multicolumn{2}{|l|}{ Child-Pugh class } \\
\hline$A$ & $50(68.5)$ \\
\hline$B$ & $19(26.0)$ \\
\hline $\mathrm{C}$ & $4(5.5)$ \\
\hline \multicolumn{2}{|l|}{ presenting symptoms } \\
\hline neurological deficits & $41(56.2)$ \\
\hline headache (\&/or nausea \& vomiting) & $21(28.8)$ \\
\hline seizure & $6(8.2)$ \\
\hline asymptomatic & $5(6.8)$ \\
\hline \multicolumn{2}{|l|}{ no. of lesions } \\
\hline 1 & $41(56.2)$ \\
\hline $2-3$ & $23(31.5)$ \\
\hline$>3$ & $9(12.3)$ \\
\hline \multicolumn{2}{|l|}{ extracranial metastases } \\
\hline lung & $36(49.3)$ \\
\hline bone & $5(6.8)$ \\
\hline lymph node & $2(2.8)$ \\
\hline multiple & $25(34.3)$ \\
\hline none & $5(6.8)$ \\
\hline \multicolumn{2}{|l|}{ KPS score } \\
\hline$\geq 70$ & $56(76.7)$ \\
\hline$<70$ & $17(23.3)$ \\
\hline \multicolumn{2}{|l|}{ RTOG RPA class } \\
\hline 1 & $2(2.8)$ \\
\hline ॥ & $55(75.3)$ \\
\hline III & $16(21.9)$ \\
\hline tumor-associated hemorrhage & $35(47.9)$ \\
\hline mean tumor vol, $\mathrm{cm}^{3}$ (range) & $7.35(0.19-33.70)$ \\
\hline \multicolumn{2}{|l|}{ tumor vol $\left(\mathrm{cm}^{3}\right)$} \\
\hline$\leq 14$ & $62(84.9)$ \\
\hline$>14$ & $11(15.1)$ \\
\hline median margin dose, Gy (range) & $23(15-32)$ \\
\hline
\end{tabular}

* Numbers of patients (\%) are indicated, unless indicated otherwise.

most common site of extracranial metastasis was the lung (36 patients, $49.3 \%$ ), and 55 patients $(75.3 \%)$ were classified as RTOG RPA Class II and 16 (21.9\%) as Class III.

\section{Tumor Control and Clinical Outcome}

The median follow-up period for all patients was 26 weeks (range 1-240 weeks). During the follow-up period, 49 patients were evaluated by MRI to assess local control of the tumor. Imaging-verified disease progression was observed in 25 of the 49 patients $(51.0 \%)$, and the median time to disease progression was 12 weeks. Local recurrences were noted in 10 patients $(20.4 \%)$ and distant recurrences in 24 patients (48.9\%). With 1 exception, all patients with local recurrences had distant recurrences. Sixteen patients with distant recurrences had a single metastasis, and 8 had multiple metastases. The estimated rate of local tumor control was $79.6 \%$ at 3 months after GKS.

During the follow-up period, 18 of the 49 patients (36.7\%) underwent repeat radiosurgery for distant recurrence, failure of local tumor control, or both. Radiationinduced severe brain edema was observed in 2 patients at 1 month or 4 months after GKS. Eleven patients (22.4\%) experienced recurrent symptomatic tumor bleeding after GKS (range 0-19 months), and 6 of these patients had tumor bleeding at the treated site. Five patients had symptomatic tumor bleeding within a month after GKS, and their prognosis was poor.

\section{Overall Survival and Prognostic Factors}

During the follow-up period, 71 patients died and 2 patients were still alive at the time of their last follow-up. There were 39 (54.9\%) systemic deaths and 26 (36.6\%) neurological deaths. The median overall survival time after GKS was 16 weeks. The actuarial survival rates were $76.7 \%, 58.9 \%$, and $26.0 \%$ at 4,12 , and 24 weeks after GKS, respectively (Fig. 1). Results for the variables analyzed for overall survival are presented in Table 2. In the univariate analysis, young age ( $\leq 65$ years), Child-Pugh Class A, a high KPS score ( $\geq 70)$, and a low RPA class (I or II) were positively associated with the survival time of

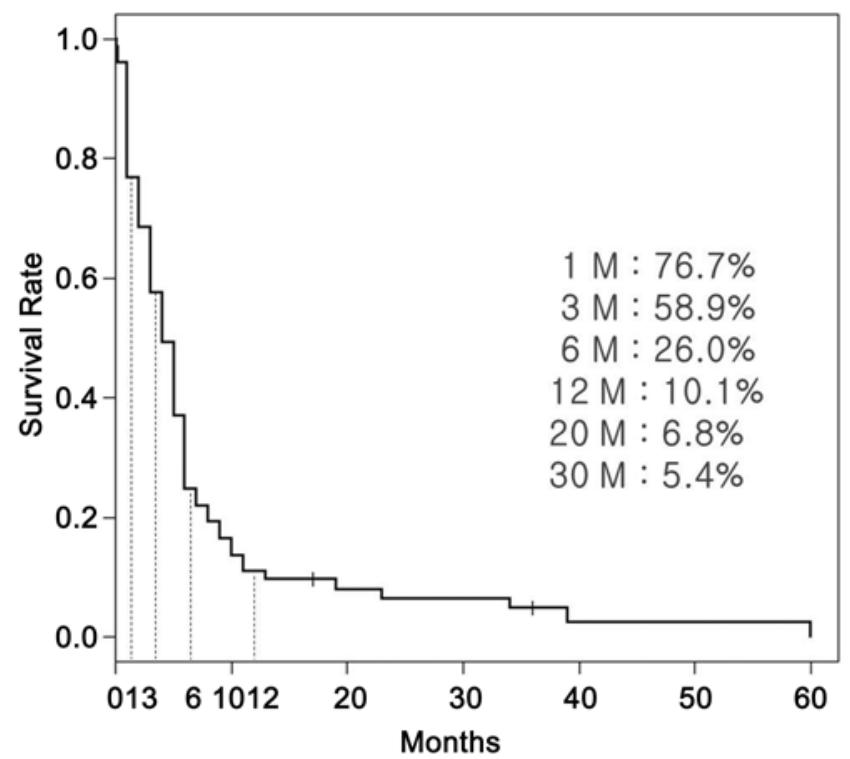

FIG. 1. Kaplan-Meier curve showing overall survival after GKS. The median overall survival time after GKS was 4 months. The actuarial survival rates were $76.7 \%, 58.9 \%, 26.0 \%, 10.1 \%, 6.8 \%$, and $5.4 \%$ at 1 , $3,6,12,20$, and 30 months after GKS, respectively. $M=$ months. 


\section{Radiosurgery of brain metastases from HCC}

TABLE 2: Univariate and multivariate analysis of prognostic factors for overall survival*

\begin{tabular}{lcccccc}
\hline & \multicolumn{2}{c}{ Univariate Analysis } & & \multicolumn{2}{c}{ Multivariate Analysis } \\
\cline { 2 - 3 } \cline { 5 - 6 } Variables & $\mathrm{HR}(95 \% \mathrm{Cl})$ & $\mathrm{p}$ Value & & $\mathrm{HR}(95 \% \mathrm{Cl})$ & $\mathrm{p} \mathrm{Value}$ \\
\hline age $(>65 \mathrm{yrs})$ & $2.09(1.02-4.28)$ & 0.045 & & $1.73(0.82-3.69)$ & 0.153 \\
AFP $(>400 \mathrm{ng} / \mathrm{ml})$ & $1.15(0.70-1.91)$ & 0.577 & & $1.07(0.63-1.81)$ & 0.805 \\
Child-Pugh Class B or C vs A & $2.35(1.39-3.99)$ & 0.001 & & $1.74(0.96-3.13)$ & 0.067 \\
single vs multiple lesions & $1.37(0.85-2.22)$ & 0.197 & & $1.31(0.79-2.17)$ & 0.294 \\
extracranial metastases & $2.37(0.85-6.61)$ & & 0.100 & & $2.11(0.73-6.11)$ & 0.167 \\
KPS score $(\geq 70)$ & $0.51(0.29-0.90)$ & 0.020 & & $0.66(0.35-1.25)$ & 0.203 \\
RTOG RPA Class III vs II/I & $1.94(1.11-3.41)$ & 0.020 & & ND & ND \\
hemorrhagic component & $1.16(0.72-1.86)$ & 0.548 & & $1.23(0.74-2.04)$ & 0.429 \\
\hline
\end{tabular}

* $\mathrm{ND}=$ not determined

the patient (Fig. 2A-D). No statistically significant variable was identified in the multivariate analysis.

\section{Illustrative Case}

A 40-year-old man, who had a 1-year history of HCC treated with abdominal radiotherapy and a history of surgery for lung metastasis, presented with headache and visual disturbance. Brain MRI scans showed an extralesional hemorrhage with a small enhancing mass in the right occipital lobe (Fig. 3A-C). Two weeks after this examination, GKS was performed. The measured tumor volume was $2.9 \mathrm{~cm}^{3}$. The tumor was covered with a $50 \%$ isodose line, and a margin dose of 25 Gy was selected. Radiosurgery was targeted only to the solid portion of the tumor and excluded an extralesional hematoma (Fig. 3D-F). The patient gradually recovered, and follow-up MRI examination 15 months later showed that the treated tumor was well controlled without local recurrence (Fig. 3J-L).

\section{Discussion}

Brain metastasis originating from $\mathrm{HCC}$ is a detrimental event that occurs late in the clinical course of $\mathrm{HCC}$, and median survival time after a brain metastasis is diagnosed is therefore expected to be short. In a previously reported series summarized in Table 3, the median survival time for patients with brain metastasis from HCCs was 4-20 weeks, ${ }^{3-8,10,23}$ which is similar to the median survival time of 16 weeks reported here. Despite this dismal prognosis, the series showed that patients whose brain tumors were treated had significantly better survival than nontreated patients. Although the data in these studies were not prospectively collected and were not from case-matched comparative studies, other studies suggest that treatments such as surgery, SRS including GKS, and WBRT have better outcomes than do conservative treatments with steroids alone. , $, 6,7,10$

To make informed treatment decisions, it is important to identify the prognostic factors for outcomes in patients with brain metastases arising from HCC. Previous reports associate favorable outcomes with several patient characteristics, including a single brain lesion, good liver func- tion according to the Child-Pugh classification, an age of $<60$ years, no recurrent intracerebral hemorrhaging, absence of extracranial metastases, a low RPA class, low AFP levels ( $\leq 400 \mathrm{ng} / \mathrm{ml})$, no intratumoral bleeding, and a low total tumor volume $\left(\leq 14 \mathrm{~cm}^{3}\right){ }^{4,5,7,10,23}$ In our study, an age of $\leq 65$ years, Child-Pugh Class A, a high KPS score $(\geq 70)$, and low RPA class (I or II) were prognostic factors for good outcomes.

The current options for managing brain metastases from HCCs are surgery, WBRT, and SRS. Resection and WBRT are at present the mainstays of management. Surgery is generally the first option in cases of a single large metastasis $(>3 \mathrm{~cm})$ with a significant mass effect (1-cm midline shift), whereas WBRT is primarily used in cases of multiple small metastases or as an adjuvant treatment. ${ }^{11,18}$ Stereotactic radiosurgery including GKS is used when the size and number of brain metastases are small. ${ }^{18}$ Compared with surgery, SRS offers noninvasive local treatment and is a better single-session, high-dose delivery system than WBRT. Because of these merits, SRS has advanced the treatment of brain metastases. Optimization of SRS to manage brain metastases from HCCs is still underway, and published experiences are very limited. In the previous reports, prescribed mean or median marginal doses range from 13.5 to $20.1 \mathrm{~Gy} .{ }^{4,5,7,10,23}$ However, as suggested by Han et al. ${ }^{5}$ and $\mathrm{Xu}$ et al., ${ }^{23}$ doses of $<20 \mathrm{~Gy}$ may be insufficient to control the lesions. Han et al. reported an imaging-defined rate of local tumor control of only $51.3 \%$ at 4 months after GKS, which they attributed to the use of a suboptimal prescribed dose..$^{5}$ In our study, the local control rate was $79.6 \%$ at 3 months after GKS. We assume that our higher rate is attributable to our use of a prescribed dose that was slightly higher than that of a referenced guideline. ${ }^{21}$

In our study, $47.9 \%$ of patients presented with hemorrhagic brain metastasis. Intratumoral bleeding, which is a peculiar characteristic of HCC brain metastasis, was also observed in approximately half of the patients (range $42.8 \%-59.1 \%$ ) in previous studies..$^{3,4,7,9,10,23}$ The hypervascularity of HCCs and the underlying coagulopathy caused by liver cirrhosis are possible causes of intratumoral bleeding. ${ }^{4}$ The presence of a hemorrhagic component can impede radiosurgical planning, as can signal changes on MRI scans and blurring of lesions. ${ }^{16}$ In addition, intratu- 
A

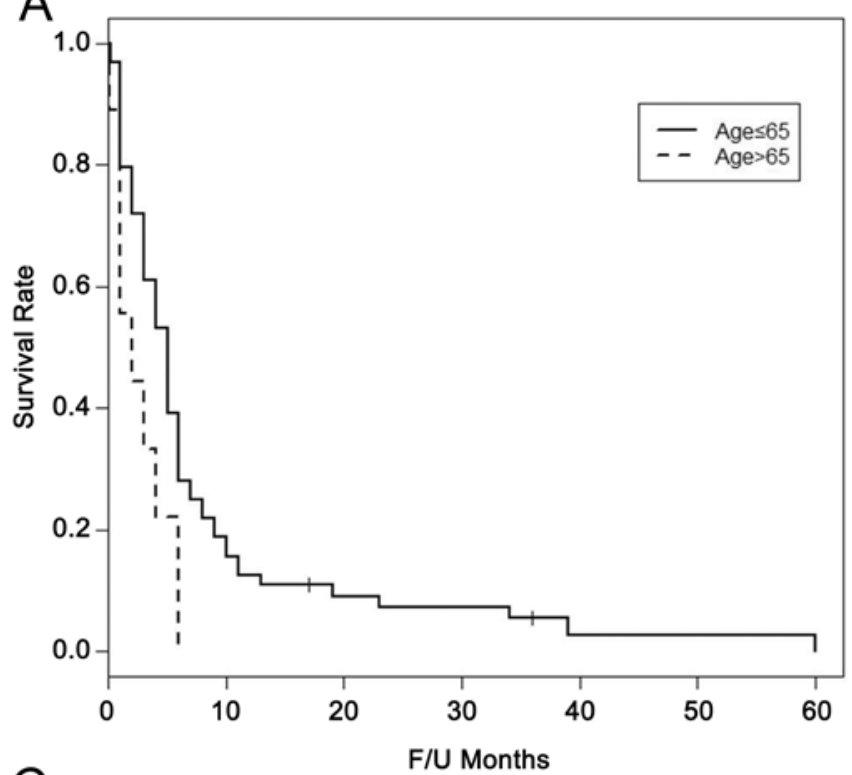

C

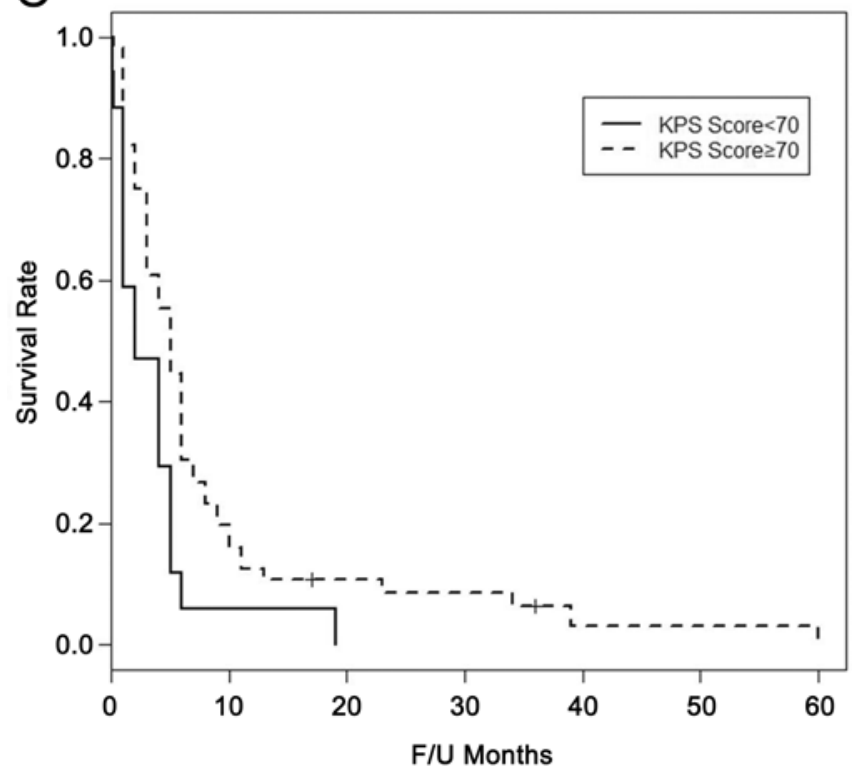

B

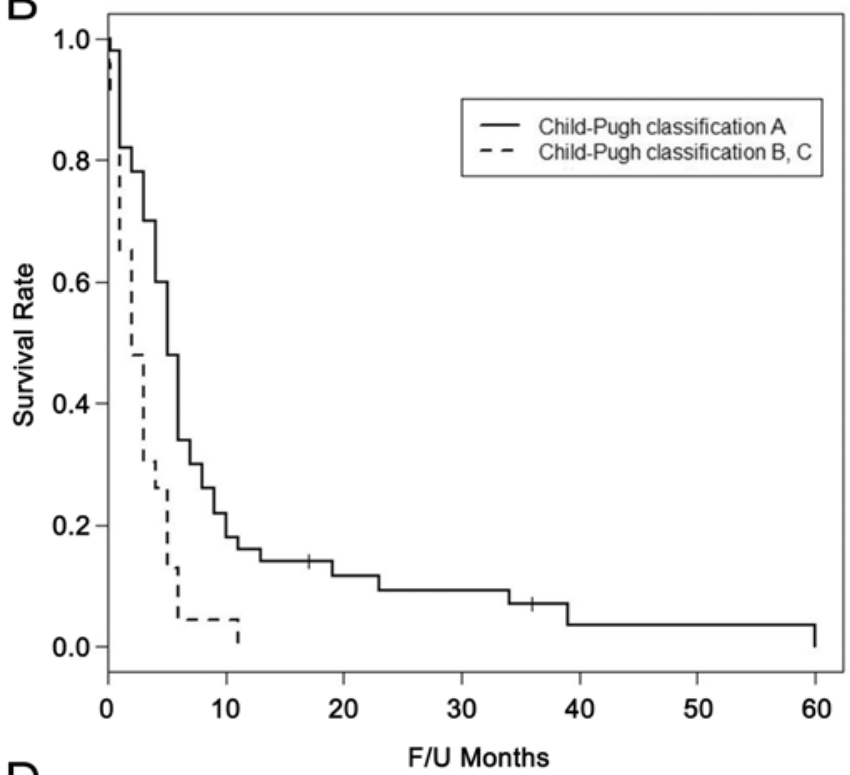

D

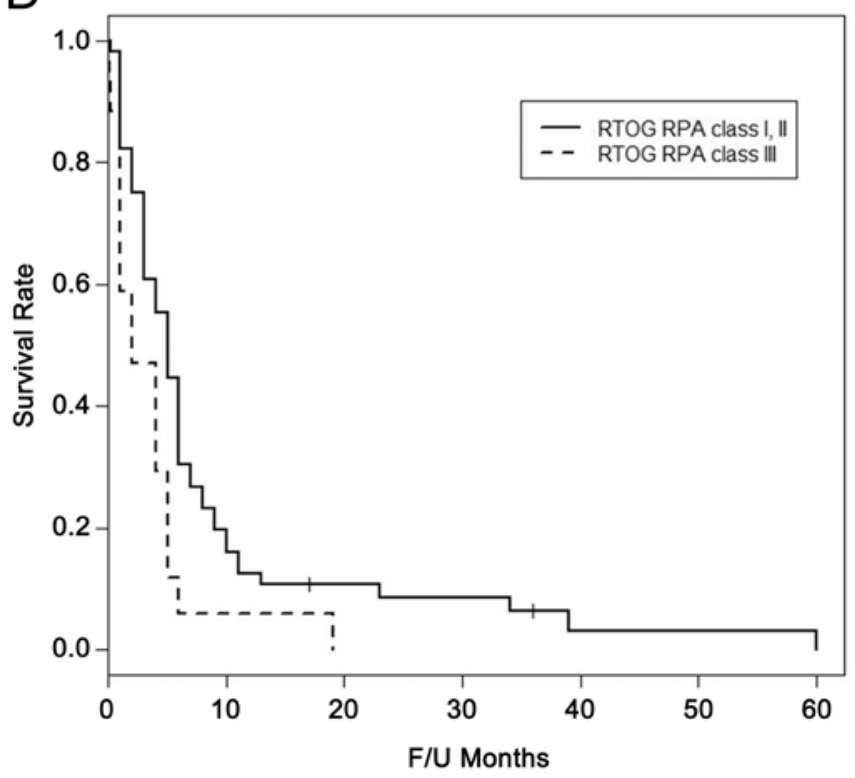

FIG. 2. Kaplan-Meier curves showing overall survival of statistically significant independent prognostic factors. F/U = followup.

moral bleeding often increases the tumor volume, which results in prescription of a relatively low marginal dose and failure of local control. ${ }^{5}$ In our opinion, accurate targeting of tumors that contain a solid enhancing portion is important for local tumor control.

We observed post-GKS peritumoral edema in cases in which overestimated tumor volume resulted in the inclusion of hemorrhagic regions. Notably, in cases where tumors were accompanied by an extralesional hemorrhage, we achieved local tumor control by targeting the solid tumors while excluding the extralesional hemorrhage (as seen in the illustrative case). We hypothesize that tumor cells that are scattered on the hematoma lack proliferative ability because they are deprived of a sufficient blood supply. Another possible explanation is radiosurgical effects on the tumor. High-dose radiation has a direct cytotoxic action on the tumor and on delayed vascular occlusion, leading to indirect tumor cell death..$^{14}$ Accordingly, highdose radiation could control not only the solid tumor but also the less viable tumor cells in the extralesional hemorrhage because of the occlusion of tumor vascularity. It was difficult to test our assumption in the present study. We expect that further studies will validate our inference about GKS planning strategies.

Another issue of intratumoral bleeding is its effect on patient survival. The effect of intratumoral bleeding of brain metastases on survival of HCC patients is controversial. ${ }^{7,9,10}$ In the present study, intratumoral bleeding before GKS had no statistically significant effects on a patient's survival. 

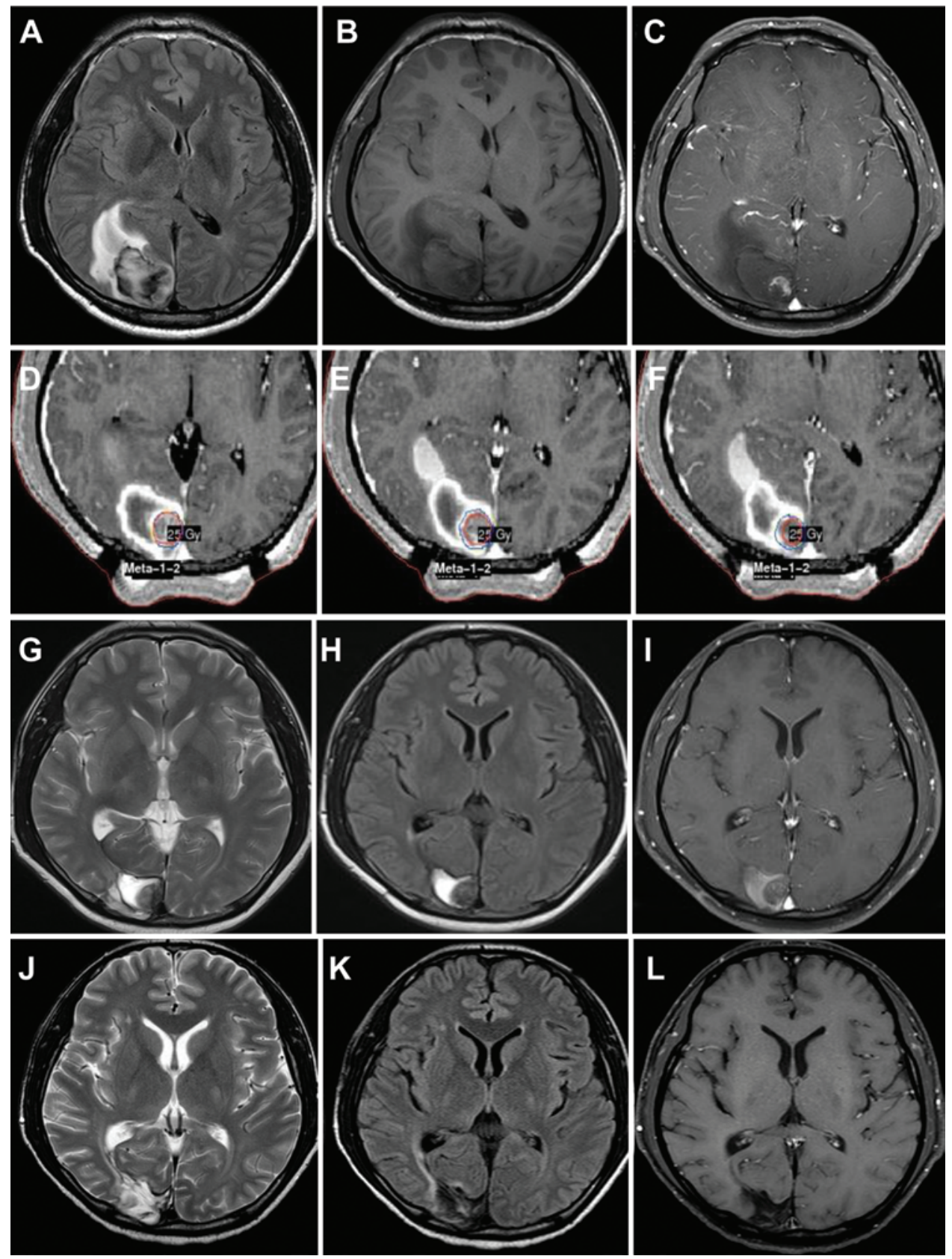

FIG. 3. Brain MRI scans of a 40 -year-old man with a history of $\mathrm{HCC}$ who presented with headache and visual disturbance. The scans revealed brain metastasis with extralesional hemorrhage in the right occipital lobe. Gamma Knife surgery was performed with $25 \mathrm{~Gy}$ at the $50 \%$ isodose line. At the time of treatment, the tumor volume was $2.9 \mathrm{~cm}^{3}$. The serial images document success in controlling the tumor locally. A-C: FLAIR (A), T1-weighted (B), and Gd-enhanced T1-weighted (C) images taken before GKS. D-F: Gd-enhanced T1-weighted images demonstrating dose planning. G-I: T2-weighted (G), FLAIR (H), and Gdenhanced T1-weighted (I) images taken 2 months after GKS. J-L: T2-weighted (J), FLAIR (K), and Gd-enhanced T1-weighted (L) images taken 15 months after GKS.

The limitations of our study are its retrospective nature, the relatively small number of patients examined, and heterogeneity of our population in terms of systemic comorbidities. However, considering that brain metastasis from $\mathrm{HCC}$ is rare, our findings are valuable for the treatment of HCC-derived brain metastases, especially with regard to GKS as a treatment option.

\section{Conclusions}

Although survival was extremely poor in patients with brain metastases arising from HCCs, GKS showed acceptable local tumor control at 3 months after treatment, especially in patients with favorable prognostic factors described above. We suggest that GKS can be a valuable 
TABLE 3: Summary observations in this and previous studies of radiosurgery for HCC-derived brain metastases*

\begin{tabular}{|c|c|c|c|c|c|c|c|c|}
\hline Authors \& Year & $\begin{array}{l}\text { No. of Patients } \\
\text { Treated w/ RS } \\
\text { (total no. of } \\
\text { patients) }\end{array}$ & $\begin{array}{l}\text { No. of } \\
\text { Mets }\end{array}$ & $\begin{array}{c}\text { RS } \\
\text { Modality }\end{array}$ & $\begin{array}{l}\text { Mean Tumor Vol } \\
\text { in } \mathrm{cm}^{3} \text { (range) }\end{array}$ & $\begin{array}{l}\text { Margin Dose in } \\
\text { Gy (range) }\end{array}$ & $\begin{array}{c}\text { Local Tumor } \\
\text { Control (\%) }\end{array}$ & $\begin{array}{l}\text { MST } \\
\text { (wks) }\end{array}$ & Factors Indicating Good Prognosis \\
\hline Chang et al., 2004 & $1(45)$ & NA & NA & NA & NA & NA & 4 & NA \\
\hline Hiraoka et al., 2008 & 1 & 1 & CKS & NA & $35 \dagger$ & 100 & NA & NA \\
\hline Choi et al., 2009 & $10(62)$ & NA & GKS & NA & $13.5(10-15)$ & NA & 6.8 & $\begin{array}{l}\text { single lesion, Child-Pugh Class } \mathrm{A} \text {, } \\
\text { any treatment modality for brain } \\
\text { mets }\end{array}$ \\
\hline Jiang et al., 2012 & $9(41)$ & 71 & NA & NA & $16(14-20)$ & NA & 12 & $\begin{array}{l}\text { no extracranial mets, low RPA } \\
\text { class, any treatment modality } \\
\text { for brain mets }\end{array}$ \\
\hline Han et al., $2013^{7}$ & $13(33)$ & NA & GKS & NA & $18(14-25)$ & NA & 10.4 & $\begin{array}{l}\text { no intratumoral bleeding, Child- } \\
\text { Pugh Class A, resection for } \\
\text { brain mets }\end{array}$ \\
\hline Xu et al., 2014 & 14 & 22 & GKS & $8.1(0.59-27)$ & $18.7(10-22)$ & NA & 20 & $\begin{array}{l}\text { tumor vol } \leq 14 \mathrm{~cm}^{3}, \text { AFP } \leq 400 \\
\text { ng/ml, RPA Class } 2\end{array}$ \\
\hline present study & 73 & 141 & GKS & $7.3(0.19-33.7)$ & $23(15-32)$ & 79.6 & 16 & $\begin{array}{r}\text { age } \leq 65 \text { yrs, Child-Pugh Class A, } \\
\text { KPS score } \leq 70 \text {, low RPA class }\end{array}$ \\
\hline
\end{tabular}

* CKS = CyberKnife radiosurgery; Mets = metastases; MST = median/mean survival time; NA = not available; RS = radiosurgery.

† A margin dose of 35 Gy in 5 fractions was used.

treatment option for patients with brain metastases from HCCs because of the noninvasive nature of GKS. Future studies should optimize doses of radiation and determine the best ways to apply GKS for the management of brain metastases from HCCs.

\section{Disclosure}

The authors report no conflict of interest concerning the materials or methods used in this study or the findings specified in this paper.

Author contributions to the study and manuscript preparation include the following. Conception and design: Kwon. Acquisition of data: ES Park, Lee. Analysis and interpretation of data: Kwon, ES Park. Drafting the article: ES Park. Critically revising the article: Kwon, JB Park, Cho, JH Kim, CJ Kim. Reviewed submitted version of manuscript: Kwon, Cho, JH Kim. Approved the final version of the manuscript on behalf of all authors: Kwon. Statistical analysis: ES Park.

\section{References}

1. Alexandru D, Bota DA, Linskey ME: Epidemiology of central nervous system metastases. Prog Neurol Surg 25:13-29, 2012

2. Benson AB III, Abrams TA, Ben-Josef E, Bloomston PM, Botha JF, Clary BM, et al: NCCN clinical practice guidelines in oncology: hepatobiliary cancers. J Natl Compr Canc Netw 7:350-391, 2009

3. Chang L, Chen YL, Kao MC: Intracranial metastasis of hepatocellular carcinoma: review of 45 cases. Surg Neurol 62:172177,2004

4. Choi HJ, Cho BC, Sohn JH, Shin SJ, Kim SH, Kim JH, et al: Brain metastases from hepatocellular carcinoma: prognostic factors and outcome: brain metastasis from HCC. J Neurooncol 91:307-313, 2009

5. Han JH, Kim DG, Chung HT, Paek SH, Park CK, Kim CY, et al: Stereotactic radiosurgery for brain metastases from hepatocellular carcinoma. J Neurooncol 115:45-51, 2013

6. Han JH, Kim DG, Park JC, Chung HT, Paek SH, Chung YS: Little response of cerebral metastasis from hepatocellular carcinoma to any treatments. J Korean Neurosurg Soc 47:325331,2010

7. Han MS, Moon KS, Lee KH, Cho SB, Lim SH, Jang WY, et al: Brain metastasis from hepatocellular carcinoma: the role of surgery as a prognostic factor. BMC Cancer 13:567, 2013

8. Hiraoka A, Horiike N, Koizumi Y, Tazuya N, Ichiryu M, Nakahara $\mathrm{H}$, et al: Brain metastasis from hepatocellular carcinoma treated with a cyber-knife. Intern Med 47:1993-1996, 2008

9. Hsieh MJ, Lu CH, Tsai NW, Lui CC, Chuang YC, Huang CR, et al: Prediction, clinical characteristics and prognosis of intracerebral hemorrhage in hepatocellular carcinoma patients with intracerebral metastasis. J Clin Neurosci 16:394-398, 2009

10. Jiang XB, Ke C, Zhang GH, Zhang XH, Sai K, Chen ZP, et al: Brain metastases from hepatocellular carcinoma: clinical features and prognostic factors. BMC Cancer 12:49, 2012

11. Kalkanis SN, Kondziolka D, Gaspar LE, Burri SH, Asher AL, Cobbs CS, et al: The role of surgical resection in the management of newly diagnosed brain metastases: a systematic review and evidence-based clinical practice guideline. J Neurooncol 96:33-43, 2010

12. Katyal S, Oliver JH III, Peterson MS, Ferris JV, Carr BS, Baron RL: Extrahepatic metastases of hepatocellular carcinoma. Radiology 216:698-703, 2000

13. Kim M, Na DL, Park SH, Jeon BS, Roh JK: Nervous system involvement by metastatic hepatocellular carcinoma. J Neurooncol 36:85-90, 1998

14. Kocher M, Treuer H, Voges J, Hoevels M, Sturm V, Müller RP: Computer simulation of cytotoxic and vascular effects of radiosurgery in solid and necrotic brain metastases. Radiother Oncol 54:149-156, 2000

15. Korean Liver Cancer Study Group, National Cancer Center, Korea: [Practice guidelines for management of hepatocellular 


\section{Radiosurgery of brain metastases from HCC}

carcinoma 2009.] Korean J Hepatol 15:391-423, 2009 (Korean)

16. Mathieu D, Kondziolka D, Cooper PB, Flickinger JC, Niranjan A, Agarwala S, et al: Gamma knife radiosurgery in the management of malignant melanoma brain metastases. Neurosurgery 60:471-482, 2007

17. Murakami K, Nawano S, Moriyama N, Sekiguchi R, Satake M, Fujimoto H, et al: Intracranial metastases of hepatocellular carcinoma: CT and MRI. Neuroradiology 38 (Suppl 1):S31$\mathrm{S} 35,1996$

18. Nabors LB, Ammirati M, Bierman PJ, Brem H, Butowski N, Chamberlain MC, et al: Central nervous system cancers. J Natl Compr Canc Netw 11:1114-1151, 2013

19. Raza A, Sood GK: Hepatocellular carcinoma review: current treatment, and evidence-based medicine. World J Gastroenterol 20:4115-4127, 2014

20. Seinfeld J, Wagner AS, Kleinschmidt-DeMasters BK: Brain metastases from hepatocellular carcinoma in US patients. $\mathbf{J}$ Neurooncol 76:93-98, 2006

21. Shaw E, Scott C, Souhami L, Dinapoli R, Kline R, Loeffler J, et al: Single dose radiosurgical treatment of recurrent previ- ously irradiated primary brain tumors and brain metastases: final report of RTOG protocol 90-05. Int J Radiat Oncol Biol Phys 47:291-298, 2000

22. Verslype C, Rosmorduc O, Rougier P, ESMO Guidelines Working Group: Hepatocellular carcinoma: ESMO-ESDO Clinical Practice Guidelines for diagnosis, treatment and follow-up. Ann Oncol 23 Suppl 7:vii41-vii48, 2012

23. Xu Q, Wu P, Feng Y, Ye K, Tong Y, Zhou Y: Gamma knife surgery for brain metastasis from hepatocellular carcinoma. PLOS ONE 9:e88317, 2014

Manuscript submitted June 30, 2014.

Accepted July 25, 2014.

Please include this information when citing this paper: DOI: 10.3171/2014.7.GKS141507.

Address correspondence to: Do Hoon Kwon, M.D., Department of Neurological Surgery, University of Ulsan College of Medicine, Asan Medical Center, Pungnap-2 dong, Songpa-gu, Seoul 138-736, Korea.email: ykwon@amc.seoul.kr. 